\title{
Variability of Track Investment with Traffic for Class I Railroads in the United States
}

\author{
Denver Tolliver, Pan Lu* \\ North Dakota State University, Fargo, USA \\ Email: Denver.Tolliver@ndsu.edu, *Pan.Lu@ndsu.edu
}

How to cite this paper: Tolliver, D. and Lu, P. (2019) Variability of Track Investment with Traffic for Class I Railroads in the United State. Modern Economy, 10, 1198-1210.

https://doi.org/10.4236/me.2019.104082

Received: March 14, 2019

Accepted: April 16, 2019

Published: April 19, 2019

Copyright $\odot 2019$ by author(s) and Scientific Research Publishing Inc. This work is licensed under the Creative Commons Attribution International License (CC BY 4.0).

http://creativecommons.org/licenses/by/4.0/

(c) (i) Open Access

\begin{abstract}
Class I railroads operate more than 191,000 kilometers of rail line in the United States, in which they have invested $\$ 196$ billion. Although these railroads are privately owned, they are regulated by the US Surface Transportation Board (STB). Some of the cost factors used by the STB in decision making are based on data from 68 to 80 years ago. These factors were developed in an era of stricter regulation, constrained business practices, low returns to investment, and lower traffic levels. In this study, new data and methods are used to assess the assumption that $50 \%$ of a railroad's investment in basic track components (such as rails, ties, and ballast) is fixed with respect to traffic. Investments in these assets are modeled as a function of traffic density, using 33 years of data for Class I railroads. A model is formulated that includes fixed effects and isolates the variation of track investment with gross tonne-kilometers. In this study, track investments are shown to be highly variable with traffic density: more so than is currently assumed. This finding has implications for regulatory practice. The $50 \%$ variable factor is used in formulas to determine if the STB has jurisdiction over a rate and, in some cases, whether the rate is reasonable.
\end{abstract}

\section{Keywords}

Railroad Track, Track Investment, Class I Railroad, Density

\section{Introduction}

In the United States, freight railroads are privately owned and operated. Nevertheless, railroads are regulated by the US Surface Transportation Board (STB), which has jurisdiction over maximum rates, mergers, acquisitions, and services. The STB regulates rates to protect shippers. However, in doing so, the agency must allow carriers to earn a rate of return at least equal to their current cost of 
capital. In implementing these differing regulations, the agency relies on estimates of variable costs, which they compare to freight rates.

The Uniform Railroad Costing System (URCS) is the general-purpose costing tool used in most regulatory proceedings [1]. URCS is a complex model that is controversial in several respects. It relies on factors developed many years ago, when there were many more railroads than there are today. The companies were much smaller, and traffic was less concentrated. A critical assumption underlying the model relates to the variability of capital investments in roadway assets. In setting maximum rates, railroads are allowed a return on $50 \%$ of their net roadway investment. This long-standing assumption (that half of road capital investments are fixed) was arrived at by the STB's predecessor, the Interstate Commerce Commission (ICC), based on traffic patterns and practices prior to 1952 [2]. Many changes have occurred since then. Deregulation has allowed railroads greater decision-making authority (especially in terms of pricing and abandoning unprofitable lines) and traffic densities have risen.

\subsection{ICC Study of Roadway Investment}

In developing the 50\% variable estimate, the ICC [2] used data from 1939 through 1951, including traffic and investment data for the World War II period. The study was based on more than 150 railroads and included many different analyses of cross-sectional and time-series data and carrier groupings. A linear regression model was used in which gross tonne-kilometers per kilometer of road were regressed against the value of the roadway (including land) and working capital per kilometer. Regressions were performed on groups of railroads, classified by average length of haul and geographic territory. The results of the individual studies varied. In some cases, roadway investments were found to be highly variable with gross tonne-kilometers. However, during the war, railroads' networks were largely fixed.

After synthesizing or selecting findings from many different analyses, the ICC [2] concluded that operating expenses were between $80 \%$ and $90 \%$ variable and plant investment was "upwards of 50 percent variable." In a report to Congress on the Uniform Railroad Costing System, the STB [3] stated that it has no plans to update the road investment factor, which is based on data from 68 to 80 years ago.

\subsection{Reasons for This Study}

The Uniform Railroad Costing System is a pivotal tool in regulatory analysis. It is used to determine if the STB has jurisdiction over a railroad rate (so that the rate can be challenged) and whether a challenged rate is reasonable under the simplified guidelines applicable to small shippers. It is not the intent of this paper to assess the adequacy or appropriateness of URCS or critique its many procedures and assumptions. This would be a voluminous undertaking. An assessment of issues and options is provided in a 2010 report to Congress by the STB 
[3]. This article focuses on an overlooked element: capital investments in track components and how they vary with traffic. URCS has been updated several times since its adoption and the expenditure functions have been re-estimated-e.g., Westbrooke [4] and ICC [5]. However, no one has reviewed or analyzed the long-standing assumption that road investments are $50 \%$ fixed.

Despite abundant criticism, URCS is still the general-purpose costing tool of the STB and is likely to remain so for the foreseeable future. Nevertheless, it is important that the assumptions and factors underlying the model be reviewed and updated. Data should be as current as possible. The dataset used in the original ICC study [2] that yielded the $50 \%$ factor is no longer available and documentation is scarce. New data and methods are introduced in this study. However, an overview of Class I railroads is presented first.

\subsection{US Class I Railroads}

The STB classifies railroads into three categories (Class I, II, and III) based on operating revenue. The seven Class I Railroads that operate in the United States are:

- The BNSF Railway Company

- CSX Transportation Company

- The Grand Trunk Corporation (GTC)

- The Kansas City Southern Railway Company (KCS)

- The Norfolk Southern Railway (NS)

- The Soo Line Corporation (SOO)

- The Union Pacific Railroad Company (UP)

Most of these companies are the result of mergers and acquisitions over time. All seven railroads meet the revenue threshold for Class I railroads ( $\$ 463.86$ million in 2017). However, there are vast differences in size and scope within this category (Table 1). The BNSF and UP operate approximately more than 50,000 kilometers of road each. In comparison, the Grand Trunk Corporation, the Kansas

Table 1. Size and scope of US Class I railroads in 2017 [6].

\begin{tabular}{cccccccc}
\hline Measure & BNSF & CSX & GTC & KCS & NS & SOO & UP \\
\hline Kilometers of road & 52.144 & 33,495 & 9452 & 5461 & 31,329 & 7783 & 51,695 \\
Miles of road & 32,401 & 20,813 & 5873 & 3393 & 19,467 & 4836 & 32,122 \\
Net investment (E6) & $\$ 62,484$ & $\$ 29,992$ & $\$ 12,981$ & $\$ 5294$ & $\$ 29,757$ & $\$ 4356$ & $\$ 50,438$ \\
Carloads originated (E3) & 9239 & 4904 & 1518 & 425 & 5142 & 488 & 6938 \\
Revenue tonne-kilometers & 972,267 & 303,850 & 91,553 & 50,490 & 294,114 & 51,455 & 681,400 \\
Revenue ton-miles (E6) & 665,949 & 208,127 & 62,709 & 34,583 & 201,452 & 35,244 & 466,721 \\
Rev. tonne-/km/km (E6) & 18.64 & 9.07 & 9.69 & 9.24 & 9.39 & 6.61 & 13.18 \\
Rev. ton-miles/mile (E6) & 20.55 & 10.00 & 10.68 & 10.19 & 10.35 & 7.29 & 14.53 \\
Gross tonne-km/km (E6) & 35.22 & 18.57 & 20.03 & 17.93 & 19.25 & 12.84 & 27.44 \\
Gross ton-miles/mile (E6) & 38.82 & 20.47 & 22.08 & 19.76 & 21.22 & 14.15 & 30.25 \\
\hline
\end{tabular}


City Southern, and the Soo Line Railroad each operate less than 10,000 kilometers. The BNSF produces 973 billion revenue tonne-kilometers of cargo, compared to 52 billion for the Soo Line. Traffic densities (as measured in gross tonne-kilometers per kilometer) vary from 12.8 million to 35.2 million.

\section{Data and Key Variables}

This study is based on reports [7] submitted by Class I railroads to the U.S. Surface Transportation Board each year. While some of the data items and accounting practices have changed over time, these reports are essentially the same ones used to derive the original factor. The reports include kilometers of road, tonne-kilometers, and investments in basic track components.

Thirty-three years of data are used in this study, ranging from 1985 through 2015. Data prior to 1985 are available. However, an important change was made in accounting practices in 1984, when railroads shifted from a betterment to a depreciation accounting basis. Reports issued prior to this date are inconsistent with subsequent reports.

Track investments made during a given year may reflect traffic demand in the recent past, as well as expected (near-term) demand. The lengthy (33-year) time period is important for several reasons. It allows long-term traffic and investment trends to be identified. Moreover, it spans an important period of economic history in the United States, in which railroads successfully made the transition from a firmly regulated industry to one with greater market freedom. Many changes in demand and general economic conditions occurred during this period.

\subsection{Net Track Investment}

The variable analyzed in this study is the sum of the net investments in rails, ties, ballast, other track materials (OTM), and grading. ${ }^{1}$ Other track materials include tie plates, spikes, anchors, and joint bars (in the case of jointed rails). Grading includes roadbed construction and reconstruction. Collectively, these elements comprise $56 \%$ of the road-related investments of Class I railroads (Figure 1). In addition to materials, capital expenditures for these items reflect labor, logistics, equipment, and other costs incurred in moving and installing the assets. However, the cost of maintaining and preserving the track is treated as an annual expense. Capital expenditures include replacements, additions, improvements, and rebuilding activities, when these activities extend the service lives of components. Repairs are classified as maintenance. Accumulated depreciation is charged against the gross investment base each year, yielding a net investment figure.

In this study, the net investment values for different years are converted to

${ }^{1}$ The raw investment data used in this study are derived from Schedule 416 of the R-1 Annual Report. The values used from that schedule are the total investment and accumulated depreciation data for track classes I and II, which include all running tracks. The accumulated depreciation is subtracted from the investment to arrive at the net investment base for each year of the analysis period. The other variables used in the study-kilometers of road and gross tonne-kilometers-are derived from Schedule 755 of the R-1 report. 


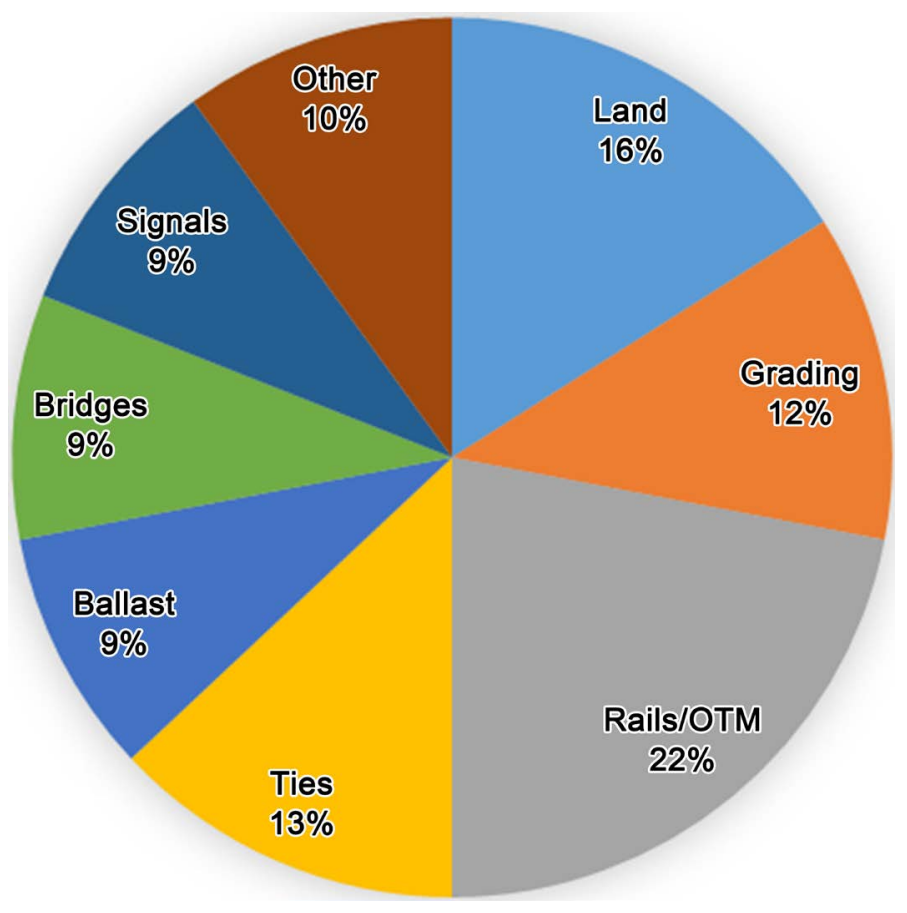

Figure 1. Components of road investment [8].

constant dollars using the Railroad Cost Recovery Index (RCRI), an index of inflation specific to Class I railroads. ${ }^{2}$ The RCRI [9] accounts for changes in the prices of inputs used by railroads, including labor, fuel, materials, supplies, purchased services, rents, and depreciation. The index increased from 116.6 in 1985 to 336.7 in 2015.

\subsection{Traffic Variables}

Revenue tonne-kilometers (a commonly used measure of railroad output) are a function of the demand for inputs, intermediate goods, and outputs within the economy. In modeling terms, revenue tonne-kilometers are exogenously determined. However, revenue tonne-kilometers reflect the weight of the cargo only. In comparison, gross tonne-kilometers (GTKM) include the weights of locomotives, freight cars, containers, trailers, and other equipment used in revenue service, as well as the distances traveled by these vehicles. These vehicle kilometers are joint activities necessary for the generation of revenue tonne-kilometers.

The difference between the two measures is most obvious in the transportation of trailers and containers. Container cargo often includes lightweight goods such as apparel and electronics. In these cases, the weight of the cargo may be a

${ }^{2}$ The process of converting the investment base in each year of the analysis period to constant dollars involves several steps. The increments to the base in each year of the period are computed by subtracting the values of the investment base and accumulated depreciation in year $t+1$ from the investment base in year $t$. Once computed in this manner, the yearly increments to the base are restated in 1985 dollars using the RCRI. The recomputed increments (in constant dollars) are then added back to the 1985 base. In this way, the additions to the base in each year of the period are stated in constant 1985 dollars. 
small percentage of the total weight of the shipment. Most of the weight is attributable to the containers and flatcars. Railway track must be designed to support gross vehicle weights, including locomotives that weigh 180 tonnes. If revenue tonne-kilometers are used as the independent variable in the model (instead of gross tonne-kilometers), it may not capture the effects of heavy loads, which are the cause of many investments to upgrade track with heavier rails and concrete ties. Figure 2 shows a clear relationship between net track investment and gross tonne-kilometers over a 33-year period for Class I railroads.

\subsection{Network Size}

Kilometers of road indicate the scope of a railroad's network. As shown in Figure 3, kilometers of road have declined over the analysis period. The reduction

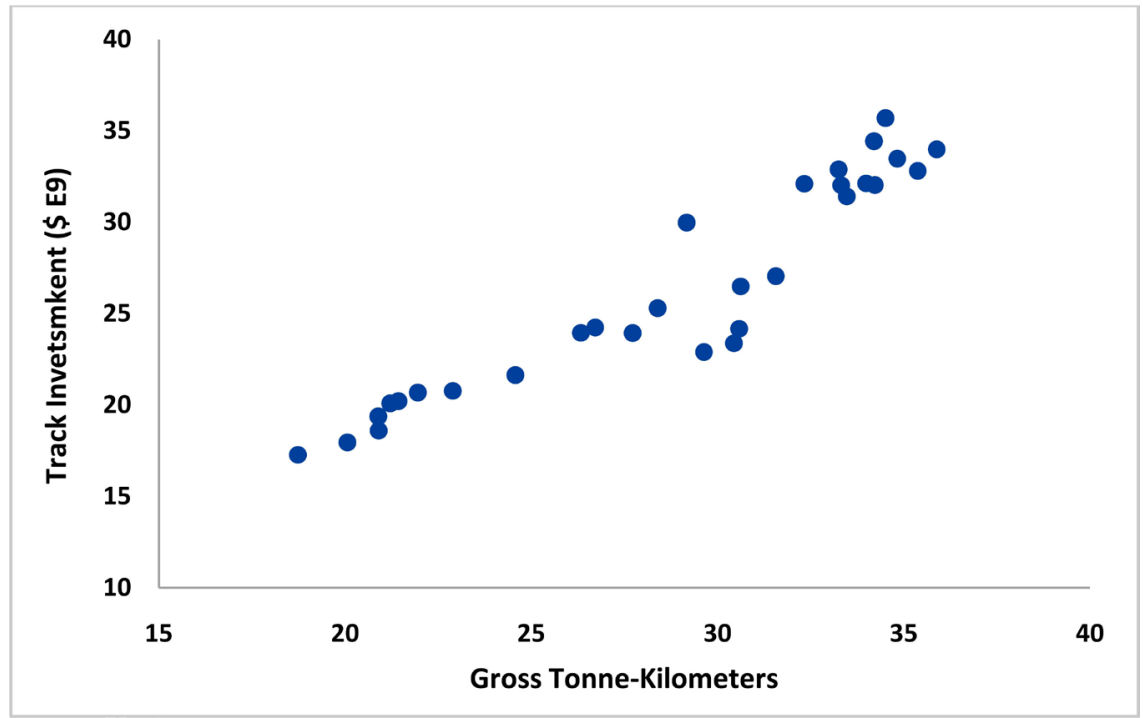

Figure 2. Net track investment versus gross tonne-kilometers for US Class I railroads (1985-2015).

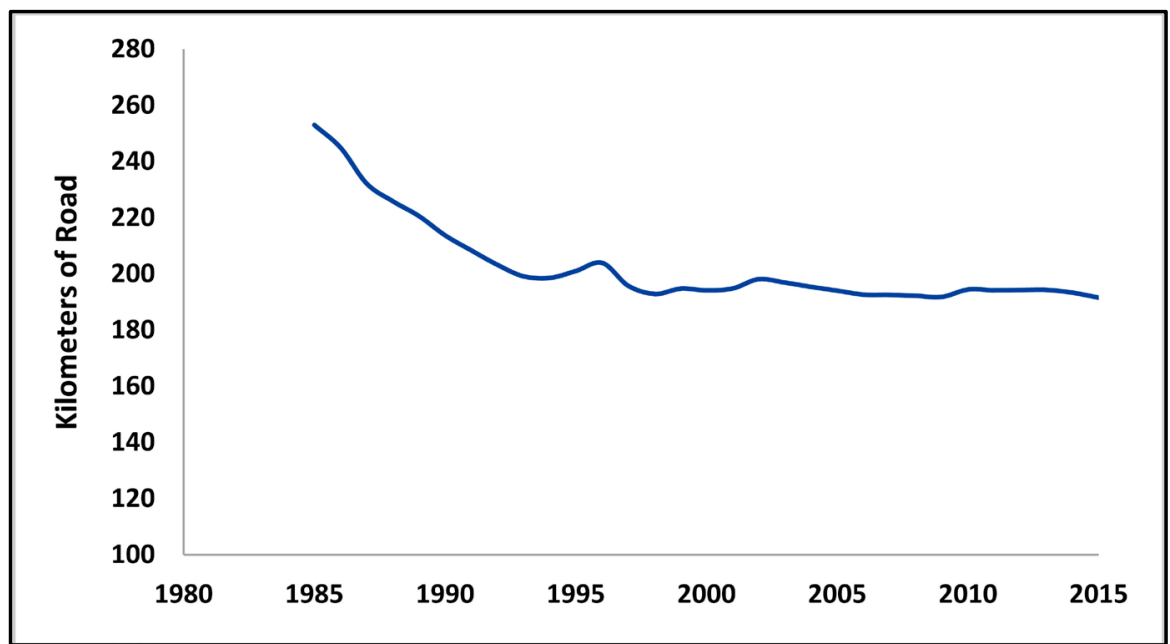

Figure 3. Changes in kilometers of road operated by Class I railroads between 1985 and 2015. 
in kilometers of road owned by Class I carriers is largely a function of line abandonments and sales. The trend has flattened since 2008, suggesting that the remaining lines under Class I ownership are viable. The large decline from 1985 to 2008 reflects a long-term adjustment to changes in regulation. In the strict regulatory environment prior to 1980 , railroads were required to keep tracks that were marginally profitable. As a result, excess capacity developed [10]. In today's flexible regulatory environment, railroads invest in roadway assets because of current and expected (near-term) traffic demand. New line construction has been minimal since 1980. Most investments are made for purposes of expanding line capacity (e.g., adding passing and side tracks) or upgrading existing tracks to handle heavier traffic and car weights.

\subsection{Traffic Density}

Traffic density reflects both gross tonne-kilometers and kilometers of road. Gross tonne-kilometers per kilometer (GTKMKM) reflect the growth and concentration of traffic on a network that is mainly fixed or shrinking, as is the case with the Class I railroad network in the United States. As shown in Figure 4, traffic density has increased from 11 million gross tonne-kilometers per kilometer (MGTKMKM) to 26 MGTKMKM over the 33-year analysis period. As shown in Table 1, current traffic densities range from 13 MGTKMKM to nearly 35 MGTKMKM for the seven Class I railroads, with a median value of 19 MGTKMKM. Historically, lines with traffic densities greater than 18 MGTKMKM have been classified as A mainlines (which is the highest classification in the network). As the trend in Figure 4 suggests, Class I railroads are targeting investments in higher-density corridors, which yield economies of utilization and scope. Density is the key factor driving investments to upgrade track quality (through newer and heavier rails, concrete ties, and other materials) or add capacity through second mainlines or passing tracks.

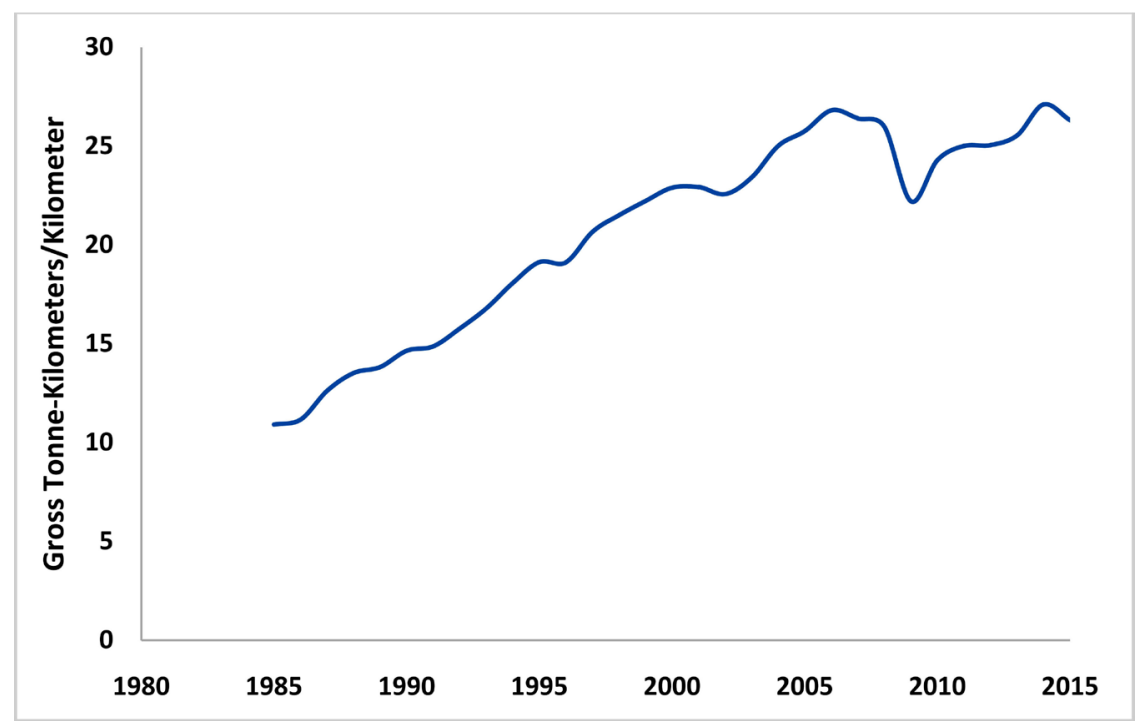

Figure 4. Trend in traffic density of US Class I railroads between 1985 and 2015. 


\section{Track Investment Model}

The basic model developed in this study is depicted in Equation (1).

$$
I M=b_{o}+b_{1} D
$$

where:

$D=$ Traffic density (gross tonne-kilometers per kilometer of road)

$I M=$ Net road investment per kilometer of road

In the statistical version of this model (shown in Equation (2)), the subscript “ $\vec{\imath}$ " denotes an observation for a particular railroad, while the subscript " $\vec{l}$ " indicates a particular year of the data series. Using this notation and letting epsilon $(\epsilon)$ represent the error term, the regression equation may be written as:

$$
I M_{i t}=\beta_{0}+\beta_{1} D_{i t}+\epsilon_{i t}
$$

Equation (2) is the same one used in the ICC's original regression [2]. However, Westbrooke [4] showed that a model like this one can be significantly improved by considering fixed railroad effects and variations across time, as depicted in Equation (3).

$$
I M_{i t}=\beta_{0}+\beta_{1} D_{i t}+\beta_{2} T_{t}+\beta_{3} F_{i}+\epsilon_{i t}
$$

The expanded model now includes an array of railroad indicator variables $\left(F_{i}\right)$. The purpose of these variables is to capture fixed effects that are specific to individual railroads, but which do not change over time. Without the indicator variables, these differential effects would be subsumed in $\beta_{0} . T$, on the other hand, accounts for industry-wide trends and changes that have occurred over time, but which are not directly measurable from the data-e.g., changes in car weights, axle loads, and operating practices. Without $T$ in the model, these effects would cloud the parameter estimates.

\subsection{Indicator Variables}

$F_{i}$ can assume values of 0 or $1 . F_{i}$ is equal to 1 when the observation comes from a particular railroad. Once $i$ is specified (i.e., the observation is determined to come from a certain railroad), the effect of $\beta_{3}$ is to shift the intercept $\left(\beta_{0}\right)$ for that railroad. Each Class I railroad that existed during the 1985-2015 period is represented by an indicator variable-e.g., KCS. When the observation is for the Kansas City Southern Railway, KCS equals 1. Otherwise, KCS equals zero.

Additional indicator variables are needed to account for mergers. The UP system includes three railroads that appear in the database: Union Pacific (UP), Southern Pacific (SP), and Chicago and North Western (CNW). CNW was acquired by UP in 1995. Union Pacific merged with Southern Pacific in 1997. In the model, UP-CNW assumes a value of 1 in 1995 and 1966 but is zero otherwise. Similarly, the variable UP-SP assumes a value of 1 in 1997, and each year thereafter-but is zero otherwise. Other mergers are handled in a similar manner. The Burlington Northern Railroad merged with the Atchison, Topeka, and Sante Fe (ATSF) to form the Burlington Northern-Sante Fe (BNSF) in 1996. CSX and the Norfolk Southern (NS) acquired parts of Conrail in 1999. In 2002, the 
Canadian National Railway consolidated the Illinois Central Gulf (ICG), Grand Trunk Western (GTW), and other rail lines into the Grand Trunk Corporation (GTC).

\subsection{Time Variable}

$T$ is an integer that measures the elapsed time in years since 1984. For example, $t$ assumes a value of 1 in 1985, 5 in 1989, 10 in 1994, and so forth. Once $t$ is specified (i.e., the observation is determined to belong to a particular year), the contribution of time is computed as $\beta_{3} \times \mathrm{t}$. Once it is computed in this manner, time shifts the intercept for a particular year. The slope of the regression is determined by density.

\subsection{Model Results}

\section{Properties and Indicators}

As shown in Table 2 and Table 3, the model has excellent statistical properties, including an R-Square of 0.92 and a coefficient of variation of $12 \%$. The model explains $92 \%$ of the variation in net track investment per mile and provides a good fit for the data. The Durbin-Watson test (Table 4) suggests that the errors are not correlated over time.

\section{Parameter Estimates}

The parameter estimates are shown in Column 2 of Table 5, along with standard errors and probability (p) values. $\mathrm{D}$ and $\mathrm{T}$ are highly significant variables, with p-values of less than 0.0001. Eleven of the railroad and merger variables are highly significant, capturing differences among railroads attributable to economic, managerial, and locational factors, as well as post-merger synthesis and rationalization. Only four of the 19 independent variables are not statistically

Table 2. Mean square error and f-value for model of track investment.

\begin{tabular}{cccccc}
\hline Source & Degrees of Freedom & Sum of Squares & Mean Square & F Value & Prob. $>$ F \\
\hline Model & 19 & $1.6147 \mathrm{E} 12$ & $849 \mathrm{E} 8$ & 175.97 & $<.0001$ \\
Error & 261 & $1.2605 \mathrm{E} 11$ & $48 \mathrm{E} 7$ & & \\
Corrected Total & 280 & $1.7408 \mathrm{E} 12$ & & & \\
\hline
\end{tabular}

Table 3. R-square and coefficient of variation for model of track investment.

\begin{tabular}{cccc}
\hline Root Mean Square Error & 21,976 & R-Square & 0.9276 \\
Coefficient of Variation (\%) & 11.8 & Adjusted R-Square & 0.9223 \\
\hline
\end{tabular}

Table 4. Results of test for serial correlation in model of track investment.

\begin{tabular}{cc}
\hline Durbin-Watson Statistic & 2.033 \\
Prob. $<$ DW & 0.6115 \\
Prob. $>$ DW & 0.3885 \\
1 $1^{\text {st }}$ Order Autocorrelation Coefficient & -0.021 \\
\hline
\end{tabular}


Table 5. Parameter estimates and standard errors.

\begin{tabular}{|c|c|c|c|c|}
\hline \multirow{2}{*}{ Variable } & \multirow{2}{*}{ Parameter Estimate } & \multicolumn{3}{|c|}{ Heteroscedasticity Consistent } \\
\hline & & Standard Error & t Value & Prob. $>|t|$ \\
\hline Intercept & $\$ 30,015.41$ & $\$ 3635.03$ & 8.26 & $<0.0001$ \\
\hline Density & $\$ 0.00258$ & $\$ 0.00027$ & 9.49 & $<0.0001$ \\
\hline $\mathrm{T}$ & $\$ 2216.44$ & $\$ 161.56$ & 13.73 & $<0.0001$ \\
\hline ATSF & $\$ 1720.58$ & $\$ 10,938.65$ & 0.16 & 0.8752 \\
\hline $\mathrm{BN}$ & $(\$ 34,199.11)$ & $\$ 4841.11$ & -7.06 & $<0.0001$ \\
\hline BNSF & $\$ 13,747.87$ & $\$ 5599.19$ & 2.46 & 0.0147 \\
\hline CNW & $(\$ 5241.90)$ & $\$ 4747.29$ & -1.10 & 0.2705 \\
\hline SP & $\$ 36,245.29$ & $\$ 5734.65$ & 6.32 & $<0.0001$ \\
\hline UP & $(\$ 14,017.55)$ & $\$ 3361.63$ & -4.17 & $<0.0001$ \\
\hline UP-CNW & $\$ 19,361.97$ & $\$ 4166.30$ & 4.65 & $<0.0001$ \\
\hline UP-SP & $(\$ 23,783.66)$ & $\$ 5946.54$ & -4.00 & $<0.0001$ \\
\hline CR & $\$ 37,732.86$ & $\$ 9703.98$ & 3.89 & 0.0001 \\
\hline CSX & $(\$ 10,486.91)$ & $\$ 6136.06$ & -1.71 & 0.0886 \\
\hline CSX-CR & $\$ 23,520.82$ & $\$ 5571.85$ & 4.22 & $<0.0001$ \\
\hline GTW & $(\$ 117,880.62)$ & $\$ 4732.37$ & -24.91 & $<0.0001$ \\
\hline GTC & $\$ 90,775.10$ & $\$ 3567.30$ & 25.45 & $<0.0001$ \\
\hline ICG & $(\$ 77,296.90)$ & $\$ 4370.11$ & -17.69 & $<0.0001$ \\
\hline NS & $\$ 16,218.45$ & $\$ 6465.38$ & 2.51 & 0.0127 \\
\hline NS-CR & $\$ 8801.12$ & $\$ 5706.07$ & 1.54 & 0.1242 \\
\hline SOO & $(\$ 31,376.22)$ & $\$ 2243.78$ & -13.98 & $<.0001$ \\
\hline
\end{tabular}

significant at the $5 \%$ level.

\section{Heteroscedasticity-Consistent Errors}

The standard errors shown in Column 3 of Table 5 are heteroscedasticity-consistent errors. They are computed under the assumption that the variance is not constant [11]. Even if heteroscedasticity exists, the regression coefficients (i.e., the parameter estimates) are not biased. However, the standard errors may be inflated, which could affect the hypothesis tests. Therefore, heteroscedasticity-consistent values are used.

In general, the standard errors in Table 5 are small in relation to the estimated parameter values. Only four of the railroad indicator variables are not statistically significant. Even if this is the result of heteroscedasticity, it does not affect the interpretation of the study, as these are control variables.

\section{Interpretation of Main Parameters}

The intercept of $\$ 30,015$ represents the net track investment per kilometer that does not vary with traffic and is not explained by one of the indicator variables: i.e., it is not a function of the characteristics of a particular railroad. It is 
Table 6. Variability of basic track investments with traffic density.

\begin{tabular}{cccccc}
\hline Density (MGTMM) & 4.5 & 11 & 18 & 27 & 36 \\
\hline Fixed Investment/Kilometer & $\$ 84,202$ & $\$ 84,202$ & $\$ 84,202$ & $\$ 84,202$ & $\$ 84,202$ \\
Variable Investment/GTKMKM & $\$ 0.007$ & $\$ 0.007$ & $\$ 0.007$ & $\$ 0.007$ & $\$ 0.007$ \\
Variable Investment/Kilometer & $\$ 36,170$ & $\$ 86,809$ & $\$ 144,681$ & $\$ 217,021$ & $\$ 289,362$ \\
Total Investment/Kilometer & $\$ 120,372$ & $\$ 171,011$ & $\$ 228,883$ & $\$ 301,224$ & $\$ 373,565$ \\
Percent Variable & $30 \%$ & $51 \%$ & $63 \%$ & $72 \%$ & $77 \%$ \\
\hline
\end{tabular}

stated in 1985 dollars. A more realistic value of $\$ 84,201$ is derived by indexing the parameter to 2017 levels using the RCRI.

When indexed to 2017 levels, the parameter estimate for GTKMKM equals 0.7 cents. This seems very small. However, average traffic densities range from 12.9 million to 35.2 million GTKMKM (Table 1). An illustration is provided in Table 6 for densities ranging from 4.5 to 36 million GTKMKM. The fixed investment is constant over this range-i.e., $\$ 84,203$ per kilometer. However, the variable portion of investment increases from $\$ 36,170$ to $\$ 289,362$ per kilometer as the density rises from 4.5 to $36 \mathrm{MGTKMKM}$. Accordingly, the percent variable increases from $30 \%$ at 4.5 MGTKMKM to $77 \%$ at 36 MGTKMKM.

Table 6 shows that the percent variable of track investments is not constant. Rather, it varies from situation to situation, which means that the percent variable will vary from year to year, from railroad to railroad, and from corridor to corridor. It only approaches $50 \%$ when the traffic density approaches 9 MGTKMKM.

The cost estimates in Table 6 are net investments that reflect accumulated depreciation. These values are significantly less than the actual (original) investments. Moreover, the estimates reflect the capitalized portion of expenditures only. Total spending on basic track components is much greater than these numbers when maintenance is considered.

\section{Track Investment Model}

The model developed in this study indicates that the variability of capital investments in basic track components is not constant. It increases with density. This is not a criticism of the ICC's study [2], which has endured for many years. However, there are vast differences between the 1939-1951 and 1985-2015 periods.

1) The time frame for the ICC's study coincided with an era of strict regulation, including entry into and exit from the industry. The abandonment of a marginal line was a complicated undertaking.

2) Railroads were initially given land grants and other incentives to build lines. Opposition to proposed abandonments was often fierce and railroads were hesitant to initiate lengthy, controversial proceedings in which they may not be successful.

3) The railroads' network was mostly fixed during World War II, which covered five of the years of the ICC's analysis period. 
4) Freight traffic levels were much lower during the time frame of the original study and fewer capacity-related expansions were needed. For example, Class I railroads transported 486,810 million revenue tonne-kilometers in 1939, as opposed to $1,280,372$ million revenue tonne-kilometers in 1985 , and 2,537,845 million revenue tonne-kilometers in 2015 [12].

5) Freight cars were much lighter during the time frame of the ICC's study. Average freight car capacities increased from 45 tonnes in 1939 to 72 tonnes in 1985, and 96 tonnes in 2015 [12]. For a given railroad network, tracks must be upgraded periodically to handle heavier carloads.

6) Railroads have much greater decision-making flexibility today. Like most businesses, railroads make capital investment decisions in response to (and in near-term expectations of) revenue growth.

7) Return on investment (ROI) has increased dramatically over time. In 1939, the railroad's ROI (as computed by the ICC) was $2.56 \%$. After railroads were partially deregulated in 1980, their ROI increased to $4.58 \%$ in 1985 and $12.1 \%$ in 2015 [12]. Railroads have more capital to invest in the modern era and have been rewarded with higher returns on investment.

The concerns brought forth in this study are not related to the model used by the ICC in its original study (although certain refinements have been demonstrated). Rather, the issues are with: a) the lumping of all roadway investments into a single category, and $b$ ) the application of a constant percent variable to all traffic densities. The model developed in this study suggests that net investments in basic track components are highly variable with traffic. These components comprise nearly $60 \%$ of the road investment base. Investments in traffic control and communication infrastructure (such as signals and interlockers) may be also highly variable with traffic. However, these investments may be correlated with train-kilometers (instead of gross tonne-kilometers). Investments in land and other types of facilities (such as bridges and tunnels) may be fixed for longer periods of time. Each type of roadway investment should be modeled in the appropriate manner.

\section{Acknowledgements}

We would like to extend our deepest appreciation and gratitude to the Mountain Plains Consortium and the US DOT University Transportation Center program for funding this research.

\section{Conflicts of Interest}

The authors declare no conflicts of interest regarding the publication of this paper.

\section{References}

[1] Interstate Commerce Commission (1989) Adoption of the Uniform Railroad Costing System as a General-Purpose Costing System for All Regulatory Costing Pur- 
poses, 5 I.C.C. $2 \mathrm{~d} 894$.

[2] Interstate Commerce Commission (1963) Explanation of Rail Cost Finding Procedures and Principles Relating to the Use of Costs. Statement No. 7-63, Washington DC.

[3] Surface Transportation Board (2010) Report to Congress Regarding the Uniform Rail Costing System.

[4] Westbrook, M.D. (1988) Uniform Railroad Costing System, Research Report. Interstate Commerce Commission, Bureau of Accounts, Washington DC.

[5] Interstate Commerce Commission (1979) Preliminary Rail Cost Study. Bureau of Account, Washington DC.

[6] Association of American Railroads (2018) Class I Railroad Statistics. Association of American Railroads, Washington DC.

[7] Surface Transportation Board (2019) Class I Railroad Annual Report (Form R1). Reports Filed by All Class I Railroads, 1985 through 2008.

[8] Surface Transportation Board (2017) Uniform Railroad Costing System Worktables. https://www.stb.gov/stb/industry/urcs.html

[9] Association of American Railroads (2018) Railroad Cost Indexes. Association of American Railroads, Washington DC.

[10] U.S. Department of Transportation (1978) A Prospectus for Change in the Freight Railroad Industry. Office of the Secretary, Washington DC.

[11] Hayes, A.F. and Cai, L. (2007) Using Heteroscedasticity-Consistent Standard Error Estimators in OLS Regression: An Introduction and Software Implementation. Behavior Research Methods, 39, 709-722. https://doi.org/10.3758/BF03192961

[12] Association of American Railroads (2018) Railroad Facts. Association of American Railroads, Washington DC. 